\title{
PENGARUH STORE LAYOUT DAN FOOD QUALITY TERHADAP MINAT BELI ULANG DAN CUSTOMER SATISFACTION PADA READY TO EAT BAKERY
}

\author{
Amadea Rahma Pambudi \\ Program Studi Manajemen, Fakultas Ekonomi, Universitas Kristen Petra \\ J1. Siwalankerto 121-131, Surabaya 60236 \\ Email: amadeapambudi@gmail.com
}

\begin{abstract}
Abstrak: Penelitian membahas pengaruh dari store layout dan food quality terhadap minat beli ulang dengan mempertimbangkan faktor customer satisfaction (Fulfillment, Pleasure, Ambivalance) pada ready to eat bakery Surabaya. Sampel penelitian ini berjumlah 100 responden pelanggan ready to eat bakery Surabaya. Hasil penelitian ini menunjukan bahwa store layout (X1) dengan dimensi alokasi luas ruangan yang tepat (X1.1) tidak berpengaruh signifikan terhadap customer satisfaction (Y), food quality (X2) dengan dimensi presentation (X2.2) berpengaruh secara positif dan signifikan terhadap customer satisfaction $(\mathrm{Y})$, dan customer satisfaction $(\mathrm{Y})$ dengan dimensi pleasure (Y1.2) berpengaruh secara positif dan signifikan terhadapminat beli ulang (Z) dengan dimensi minat transaksional (Z1.1).
\end{abstract}

Kata kunci: Ready to eat bakery; store layout; food quality; customer satisfaction; minat beli ulang.

\begin{abstract}
The research discusses the effect of store layout and food quality on buying interest by considering customer satisfaction factor (Fulfillment, Pleasure, Ambivalance) at ready to eat bakerySurabaya. The sample of this study amounted to 100 respondents ready to eat bakerySurabaya customers. The result of this research shows that store layout (X1) with appropriate space allocation dimension (X1.1) has no significant effect on customer satisfaction (Y), food quality (X2) with presentation dimension (X2.2) have positive and significant influence To customer satisfaction $(Y)$ and customer satisfaction (Y) with pleasure dimensions (Y1.2) have a positive and significant effect on repurchase interest (Z) with transactional interest dimension (Z1.1).
\end{abstract}

Keywords: Ready to eat bakery; store layout; food quality; customer satisfaction; repurchase intention.

\section{PENDAHULUAN}

Peluang bisnis ritel di Indonesia tumbuh sangat pesat, terutama pertumbuhan kelas menengah dan menengah ke atas. Menurut McKinsey ("Tren Ritel di Indonesia," 2016), diperkirakan pada tahun 2030 mendatang masyarakat urban akan mengalami pergeseran biaya belanja 9 persen dari produk makanan ke produk non-makanan. Namun, makanan dan minuman tetap akan menjadi pasar yang menarik dan memiliki potensi pengeluaran terbesar peringkat dua pada tahun 2030. Segmen makanan dan minuman bertumbuh sebesar 5,2 persen per tahun hingga tahun 2030.

Pertumbuhan bisnis ritel di Indonesia membawa keberuntungan bagi pelaku bisnis kuliner di Indonesia. Salah satu pertumbuhan bisnis kuliner yang mencengangkan adalah bisnis ritel bidang bakerydi Indonesia yang semakin banyak bermunculan dan menjanjikan. Perkembangan dunia bakery sendiri didukung dengan berkembangnya kreatifitas dan inovasi yang terus dilakukan dalam menciptakan menu-menu andalan.

Store layout (tata letak) lebih baik dibentuk bervariasi agar membuat pelanggan berpindah-pindah memutari keseluruhan toko.Kesesakan di dalam toko adalah salah satu hal yang harus dihindari, karena berpengaruh pada emosi dan kepuasan pelanggan (Goswami, Gupta, \& Professors, 2013).

(Shaharudin, Mansor, \& Elias, 2011), kualitas makanan adalah kunci penting bahwa pelanggan akan selalu mencari untuk memenuhi kebutuhan dan harapan mereka terhadap restoran yang mereka pilih. Untuk memenangkan persainganpasar saat ini, pemilik restoran telah mengambil upaya dengan menawarkan baikpada nilai makanan mereka juga menyediakan pelanggan dengan suasana yang menguntungkan.

Hubungan kepuasan pelanggan dan terjadinya minat beli ulang menurut (Ibzan, Balarabe, \& Jakada, 2016) melalui penelitian longitudinal dan crosssectional untuk kepuasan-pembelian kembali menunjukkan bahwa konsumen yang puas lebih memungkinkan untuk melanjutkan hubungan mereka dengan organisasi tertentu daripada yang tidak puas didukung oleh sejumlah peneliti.

Oleh karena itu, peneliti ingin membuktikan pengaruh store layout dan food quality terhadap minat beli ulang dan customer satisfaction pada ready to eat bakery industries. 


\section{LANDASAN TEORI}

\section{Store Layout}

Pemilihan jenis tata letak (Elbers, 2016) toko harus bisa menyampaikan gambaran toko ritel seperti apa yang konsumen masuki. Tata letak dengan bentuk bervariasi dimaksudkan agar pelanggan tidak hanya membeli produk yang sudah direncanakan saja lalu pulang, namun diharapkan dengan tata letak yang bervariasi dapat merangsang keinginan pelanggan memutari toko secara keseluruhan. Tidak kalah penting mengenai efisiensi dalam merancang tata letak toko harus memberikan kontribusi untuk penjualan produk dan profitabilitas toko. Store layout memiliki dimensi alokasi luas ruangan yang tepat, penempatan meja/kursi yang tepat, dan lokasi penempatan ruangan yang baik.

\section{Food Quality}

(Shaharudin et al., 2011) kualitas makanan sangat penting karena pelanggan akan selalu mencari untuk memenuhi kebutuhan dan harapan mereka terhadap restoran yang mereka pilih. Dalam memilih makanan biasanya, pelanggan akan membentuk nilai dan harapan mereka sendiri pada berbagai macam menu yang disajikan di sebuah restoran. Food quality memiliki dimensi temperature, presentation, тепи variety, dan tastiness.

\section{Customer Satisfaction}

Kepuasan pelanggan (Al-Msallam, 2015) adalah peranan penting dalam dunia pemasaran, untuk memprediksi perilaku pembelian seperti; minat beli ulang, minat beli, pemilihan merek dan perubahan perilaku. Kepuasaan seseorang dapat dilihat dari kesenangan atau kekecewaan berdasarkan hasil yang dirasakan dari produk atau jasa, apakah sesuai dengan yang diharapkan oleh pelanggan. Kepuasaan pelanggan merupakan umpan balik untuk mengidentifikasi masalah dan peluang yang ada. Kepuasan juga dianggap evaluasi secara keseluruhan setelah melakukan pembelian. Customer satisfaction memiliki dimensi fulfillment, pleasure, dan ambivalence.

\section{Repurchase Intention}

Minat beli ulang merupakan suatu tindakan nyata konsumen dalam mengambil keputusan untuk kembali terlibat pada kegiatan di masa depan dengan pengecer (Ibzan et al., 2016). Dua bentuk minat beli ulang yaitu; niat membeli kembali dan niat terlibat positif dalam World of Mouth (WOM). Minat beli ulang terjadi, jika pengecer dapat membangun dan mengelola hubungan baik dengan pelanggan. Pengecer harus selalu beradaptasi dengan perubahan-perubahan yang terjadi pada pelanggan, terus memberikan nilai-nilai dan selalu berusaha meningkatkan kepuasan pelanggan. Repurchase intention memiliki dimensi minat transaksional, minat referensial, minat preferensial, dan minat eksploratif.

\section{Kerangka Konseptual}

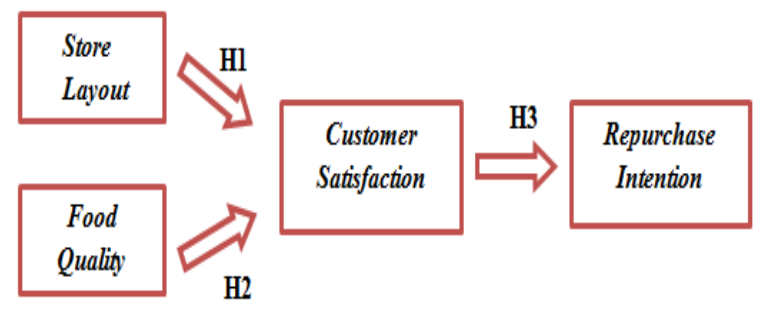

Gambar 1. Kerangka Konseptual

\section{Hipotesa}

H1: Store layout berpengaruh secara negatif terhadap customer satisfaction.

H2: Food quality berpengaruh secara positif terhadap customer satisfaction.

H3: Customer satisfaction berpengaruh secara positif terhadap repurchase intention.

\section{METODE PENELITIAN}

\section{Populasi}

Populasi adalah keseluruhan dari semua elemen yang memiliki beberapa karakteristik umum, terdiri dari alam semesta bertujuan untuk masalah riset pemasaran (Malholtra, 2004). Populasi dalam penelitian ini adalah semua konsumen yang pernah berkunjung dan melakukan pembelian di ready to eat bakery di Surabaya.

\section{Sampel}

Sampel adalah bagian dari jumlah dan karakteristik yang ada dari populasi (Sugiyono, 2007). Teknik pengambilan sampel dalam penelitian ini adalah Non-Probability Sampling dengan cara Purposive Sampling. Purposive Sampling merupakan pelanggan ready to eat bakery di Surabaya yang berdomisili di Surabaya dan pernah melakukan transaksi pembelian antara bulan Desember 2017 hingga Maret 2018. 


\section{Definisi Operasional Variabel}

\section{Store Layout (X1)}

a. Alokasi Luas Ruangan yang Tepat (X1.1) Dalam mengatur luas ruang pengecer harus mengetahui dan menyesuaikan kebutuhan ruang per bagian, bagian mana yang memerlukan ruang lebih luas atau lebih kecil.

b. Penempatan Meja/Kursi yang Tepat (X1.2) Mengatur daerah meja/kursi pengecer harus menempatkannya di bagian yang tidak membuat area berjalan bentrok atau terganggu dengan area meja/kursi.Memilih area yang tepat, santai dan nyaman untuk konsumen duduk dan menikmati suasana toko.

c. Lokasi Penempatan Ruangan yang Baik (X1.3)

Menciptakan suasana yang ingin ditampilkan pengecer tentang toko.

2. Food Quaity (X2)

a. Temperature (X2.1)

Merupakan elemen sensorik kualitas makanan.

b. Presentation (X2.2)

Salah satu fitur faktor makanan dalam pemodelan kepuasan makan dan pelanggan kembali.

c. Menu Variety (X2.3)

Mengembangkan menu baru untuk menarik pengunjung dan sebagai bentuk proaktif pemilik restoran yang telah menciptakan berbagai macam persembahan makanan dan minuman.

d. Tastiness (X2.4)

Atribut kunci dalam makanan dalam pengalaman bersantap.

3. Customer Satisfaction (Y)

a. Fulfillment (Y1.1)

Mengacu pada tingkat kepuasan atau rasa yang muncul akan kebutuhan yang telah terpenuhi.

b. Pleasure (Y1.2)

Mengacu pada tingkat kepuasan dengan perasaan senang dalam layanan yang membuat konsumen merasa baik atau bahagia.

c. Ambivalence (Y1.3)

Mengacu terhadap adanya campuran pengalaman positif dan negatif terkait dengan produk atau jasa.

4. Repurchase Intention $(\mathrm{Z})$

a. Minat Transaksional (Z1.1)

Seseorang cenderung selalu membeli ulang produk yang telah dikonsumsinya.

b. Minat Referensial (Z1.2)

Seseorang cenderung mereferensikan produk yang sudah dibeli, agar dibeli juga olehorang lain, dengan referensi pengalaman konsumsinya. c. Minat Preferensial (Z1.3)

Perilaku seseorang yang selalu memiliki preferensi utama pada produk yang pernah dikonsumsi. Hanya akan mengganti produk jika terjadi sesuatu dengan produk preferensinya.

d. Minat Eksploratif (Z1.4)

Seseorang yang selalu mencari informasi mengenai produk yang diminati dan informasi yang mendukung sifat-sifat positif dari produk langganannya.

\section{Alat analisa}

\section{Path Analysis}

Pengujian hipotesis penelitian ini menggunakan teknik path analysis dalam menunjukkan adanya hubungan yang kuat antar variabel-variabel yang diuji. Teknik path analysis digunakan untuk menggambarkan dan menguji model hubungan antar variabel sebab-akibat (Sugiyono, 2007). Teknik path analysis merupakan pengembangan korelasi yang diurai menjadi beberapa interpretasi akibat yang ditimbulkan. Pengujian statistic model path analysis dilakukan dengan menggunakan model partial least square. Partial Least Square (PLS) merupakan bagian dari SEM (Structural Equation Model). Merupakan teknik statistika yang tidak membutuhkan distribusi normal, dapat dikatakan sebuah penelitian dengan jumlah sampel yang sedikit Abdillah, W., \& Hartono, J. (2015).

\section{T-test}

Pengujian hipotesis mediasi (variabel intervening) dilakukan dengan prosedur t-test, untuk mendapatkan nilai t-statistik yang diperlukan, peneliti dapat mengatakan pengaruh sebuah variabel memiliki pengaruh yang signifikan atau tidak.T-test dilakukan dengan menggunakan metode bootstrapping .

Metode bootstrapping adalah proses pengujian re-sampling yang dilakukan oleh sistem komputer untuk mengukur akurasi pada sampleestimate, digunakan untuk mengukur akurasi pada sample. Apabila nilai bootstrap lebih dari (>) 1.96 dinyatakan bahwa variabel tersebut memiliki pengaruh yang signifikan, sedangkan nilai bootstrap lebih rendah $(<)$ dari 1.96, dinyatakan pengaruh variabel tersebut lemah. (Abdillah, W., \& Hartono, 2015)

\section{Statistik Deskriptif}

Statistik deskriptif adalah statistik yang digunakan untuk menganalisa data dengan mendeskripsikan 
data yang telah terkumpul dan digunakan untuk menarik kesimpulan dari hasil penelitian melalui kusioner yang telah dilakukan.

\section{ANALISA DAN PEMBAHASAN}

\section{Profil Responden}

Tabel 1. Usia Pelanggan

\begin{tabular}{ccc}
\hline Jangka Waktu & Frequency & Prosentase (\%) \\
\hline $17-20$ tahun & 16 & $16 \%$ \\
$21-30$ tahun & 53 & $53 \%$ \\
$31-40$ tahun & 24 & $24 \%$ \\
$41-50$ tahun & 3 & $3 \%$ \\
$>50$ tahun & 4 & $4 \%$ \\
Total & 100 & $100 \%$ \\
\hline
\end{tabular}

Menjelaskan mayoritas responden didominasi oleh kelompok usia 21-30 tahun dengan prosentase 53\% dan diikuti usia 31-40 tahun dengan prosentase $24 \%$. Kebanyakan pelanggan dari ready to eat bakery di Surabaya adalah kelompok usia dewasa.

Tabel 2. Total Pembelian Produk

\begin{tabular}{ccc}
\hline $\begin{array}{c}\text { Jumlah Pembelian } \\
\text { Produk }\end{array}$ & Frequency & Prosentase (\%) \\
\hline 1 kali & 38 & $38 \%$ \\
$2-4$ kali & 51 & $51 \%$ \\
$>5$ kali & 11 & $11 \%$ \\
Total & 100 & $100 \%$ \\
\hline
\end{tabular}

Menjelaskan dalam kurun waktu 4 bulan, responden yang melakukan pembelian produk ready to eat bakerydi Surabaya sebanyak 1 kali sebesar 38\%, 2-4 kali sebesar 51\% dan >5 kali sebesar $11 \%$.

\section{Analisa Deskriptif}

Tabel 3. Analisa Deskriptif Dimensi Alokasi Luas Ruangan yang Tepat

\begin{tabular}{cccccccc}
\hline \multirow{2}{*}{ Indikator } & \multicolumn{9}{c}{ Jawaban } & & \multirow{2}{*}{ Mean } & Std. Dev. \\
\cline { 2 - 7 } & STS & TS & $\mathbf{N}$ & S & SS & & \\
\hline $\mathrm{X} 1.1 .1$ & 0 & 0 & 13 & 51 & 36 & 4,23 & 0,661 \\
$\mathrm{X} 1.1 .2$ & 0 & 0 & 6 & 56 & 38 & 4,32 & 0,581 \\
$\mathrm{X} 1.1 .3$ & 0 & 0 & 15 & 50 & 35 & 4,2 & 0,678 \\
\hline
\end{tabular}

X1.1.1 nilai mean 4,23 dengan standar deviasi 0,661, artinya secara umum responden setuju bahwa ready to eat bakerySurabaya memiliki luas ruangan yang nyaman. Ready to eat bakery Surabaya memperhatikan dan menyediakan ruang yang cukup luas, agar pelanggan leluasa saat berada di outletready to eat bakery Surabaya.
X1.1.2 nilai mean 4,32 dengan standar deviasi 0,581 , artinya pada umumnya semua responden setuju bahwa produk-produk ready to eat bakery Surabaya dikelompokkan sesuai jenisnya. Hal ini didasari agar pelanggan ready to eat bakery Surabaya lebih mudah untuk mencari dan berbelanja jenis produk yang mereka inginkan.

X1.1.3 nilai mean 4,2 dengan standar deviasi 0,678 , artinya secara garis besar responden setuju bahwa lokasi antar kelompok produk ready to eat bakery Surabaya mudah dijangkau. Jarak tempuh antar kelompok produk tidak terlalu jauh.

Tabel 4. Analisa Deskriptif Dimensi Presentation

\begin{tabular}{cccccccc}
\hline \multirow{2}{*}{ Indikator } & \multicolumn{9}{c}{ Jawaban } & \multirow{2}{*}{ Mean Std. Dev. } \\
\cline { 2 - 7 } STS & TS & N & S & SS & & \\
\hline X2.2.1 & 0 & 0 & 8 & 39 & 53 & 4,45 & 0,638 \\
X2.2.2 & 0 & 0 & 7 & 45 & 48 & 4,41 & 0,618 \\
X2.2.3 & 0 & 0 & 7 & 47 & 46 & 4,39 & 0,615 \\
X2.2.4 & 0 & 0 & 9 & 44 & 47 & 4,38 & 0,645 \\
\hline
\end{tabular}

X2.2.1 nilai mean 4,45 dengan standar deviasi 0,638 , artinya secara umum responden setuju bahwa penampilan penyajian ready to eat bakery Surabaya mengundang selera makan. Melalui penampilan dan penyajian produk ready to eat bakery Surabaya yang bersih dan menarik akan menciptakan dan mengundang selera makan pelanggan.

X2.2.2 nilai mean 4,41 dengan standar deviasi 0,618 , artinya pada umumnya semua responden setuju bahwa kombinasi warna ready to eat bakery Surabaya menarik. Kombinasi warna yang dipilih oleh ready to eat bakery Surabaya dapat memikat pelanggan dan menjadikan pelanggan ingin memakan dan membelinya.

X2.2.3 nilai mean 4,39 dengan standar deviasi 0,615 , artinya secara garis besar responden setuju bahwa bentuk fisik ready to eat bakery Surabaya unik. Bentuk fisik ready to eat bakery Surabaya terdiri dari persegi, persegi panjang, lingkaran, dan bisa custom untuk custom cake.

X2.2.4 nilai mean 4,38 dengan standar deviasi 0,645 , artinya secara garis besar responden setuju bahwa penataan ready to eat bakery Surabaya disajikan secara menarik. Dimana penataan ready to eat bakery Surabaya ditata sedemikian rupa menarik agar dapat menarik perhatian pelanggan untuk mencoba dan membeli ready to eat bakery Surabaya.

Tabel 5. Analisa Deskriptif Dimensi Pleasure

\begin{tabular}{cccccccc}
\hline \multirow{2}{*}{ Indikator } & \multicolumn{5}{c}{ Jawaban } & \multirow{2}{*}{ Mean } & \multirow{2}{*}{ Std.Dev. } \\
\cline { 2 - 6 } & STS & TS & N & S & SS & & \\
\hline Y1.2 & 0 & 0 & 9 & 55 & 36 & 4,27 & 0,614 \\
\hline
\end{tabular}


Y1.2 nilai mean 4,27 dengan standar deviasi 0,614 , artinya secara umum responden setuju bahwa pelanggan merasa senang bertransaksi dengan ready to eat bakerySurabaya. Pelanggan ready to eat bakery Surabaya tidak melihat adanya hal yang buruk selama bertransaksi dengan ready to eat bakery Surabaya.

Tabel 6. Analisa Deskriptif Dimensi Minat Transaksional

\begin{tabular}{|c|c|c|c|c|c|c|c|}
\hline \multirow{2}{*}{ Indikator } & \multicolumn{5}{|c|}{ Jawaban } & \multirow[b]{2}{*}{ Mean } & \multirow{2}{*}{ Std. Dev. } \\
\hline & STS & TS & $\mathbf{N}$ & $\mathbf{S}$ & SS & & \\
\hline Z1.1 & 0 & 0 & 5 & 57 & 38 & 4,33 & 0,567 \\
\hline
\end{tabular}

Z1.1 nilai mean 4,33 dengan standar deviasi 0,567 , artinya secara umum responden setuju bahwa pelanggan akan membeli ulang produk sejenis pada ready to eat bakery Surabaya. Pelanggan ready to eat bakerySurabaya yang puas dengan produk sejenis akan melakukan pembelian ulang pada produk yang sama di ready to eat bakery Surabaya.

\section{Evaluasi Path Coefficient dan Coefficient of Deter- mination}

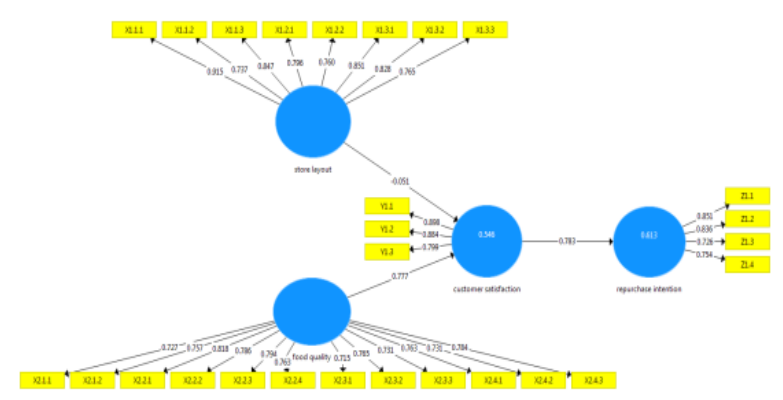

Gambar 2. Path Coefficient dan Coefficient of Determination

Analisa path coefficient terbukti bahwa customer satisfaction merupakan variabel intervening yang tidak memperkuat hubungan store layout dengan repurchase intention sebesar $-0,039$ yang merupakan hasil perkalian $-0,051$ dan 0,783 , dan merupakan variable intervening yang memperkuat hubungan food quality dengan repurchase intention sebesar 0,608 yang merupakan hasil perkalian 0,777 dan 0,783 .

Merupakan bukti hubungan store layout terhadap customer satisfaction sebagai variabel intervening tidak dapat memperkuat hubungan dengan repurchase intention karena memberikan hubungan yang lemah. Melainkan hubungan food quality terhadap customer satisfaction sebagai variabel intervening dapat memperkuat hubungan dengan repurchase intention.

Nilai coefficient of determination $\left(\mathrm{R}^{2}\right)$ pada angka di dalam lingkaran customer satisfaction yang dipengaruhi oleh store layout dan food quality sebesar 0,546 . Artinya variabelstore layout dan food quality dijelaskan customer satisfaction sebesar 54,6\% sedangkan 45,4\% lainnya dijelaskan oleh variabel lain di luar penelitian. Variable repurchase intention yang dipengaruhi oleh customer satisfaction sebesar 0.613. Artinya variable customer satisfaction mempengaruhi repurchase intention sebesar $61,3 \%$ sedangkan $38.7 \%$ lainnya dipengaruhi oleh variabel lain di luar penelitian.

\section{T-statistic}

Tabel 7. T-statistic

\begin{tabular}{cccccc}
\hline & $\begin{array}{c}\text { Original Sample } \\
\text { Sample } \\
(\mathbf{O})\end{array}$ & $\begin{array}{c}\text { Mean } \\
(\mathbf{M})\end{array}$ & $\begin{array}{c}\text { Standard } \\
\text { Deviation } \\
(\mathbf{S T D E V})\end{array}$ & $\begin{array}{c}\text { T Statistics } \\
(\mid \mathbf{O} \text { STDEV|) }\end{array}$ & $\begin{array}{c}\mathbf{P} \\
\text { Values }\end{array}$ \\
\hline $\begin{array}{c}\text { SL (X1) } \rightarrow \\
\text { CS (Y) }\end{array}$ & $-0,05$ & $-0,06$ & 0,11 & 0,46 & 0,64 \\
$\begin{array}{c}\text { FQ (X2 } \rightarrow \\
\text { CS (Y) }\end{array}$ & 0,78 & 0,79 & 0,09 & 9,09 & 0,00 \\
$\begin{array}{c}\text { CS (Y) } \rightarrow \\
\text { RI (Z) }\end{array}$ & 0,78 & 0,79 & 0,04 & 19,86 & 0,00 \\
\hline
\end{tabular}

Memiliki arti nilai original sampel (O) adalah nilai path coefficient yang menunjukan kekuatan pengaruh satu latent variable ke satu latent variable lainnya. Nilai mean (M) menunjukan nilai tengah dari path coefficient. Standar deviasi (STDEV), menunjukkan nilai simpang pada sampel mean. Nilai $T$-statistic untuk melihat nilai $\mathrm{T}$ hitung yang digunakan pada pengujian hipotesis, $T$-statistic harus $>1,96$.

$T$-statistic pada pengaruh store layout terhadap customer satisfaction menunjukan 0,46yang artinya store layout tidak berpengaruh signifikan terhadap customer satisfaction, dan mempunyai hubungan yang lemah terhadap customer satisfaction. T-statistic pada pengaruh food quality terhadap customer satisfaction menunjukan 9,09 yang artinya food quality berpengaruh signifikan terhadap customer satisfaction. T-statistic pada pengaruh customer satisfaction terhadap repurchase intention menunjukan 19,86 yang artinya customer satisfaction berpengaruh signifikan terhadap repurchase intention.

\section{PEMBAHASAN}

\section{Store layout terhadap Customer Satisfaction}

Penelitian ini memiliki hasil bahwa store layout ready to eat bakery Surabaya tidak memiliki pengaruh terhadap customer satisfaction secara signifikan dengan nilai uji $T$-statistic $>1.96$ yaitu 0,46 .

Hipotesis awal peneliti, bahwa store layout berpengaruh signifikan terhadap customer satisfaction 
yang didukung oleh pendapat (Sihombing \& Djatikusuma, 2014) mengenai pengaruh citra toko terhadap kepuasan konsumen, dan (Arshad, Sabir, \& Zia, 2014) bahwa aspek fisik penentu pertama dari kepuasan pelanggan, dimana mayoritas responden setuju bahwa aspek fisik dari toko harus baik secara tampilan, struktur fisik nyaman, bersih, dan tata letak harus memudahkan pelanggan bergerak di sekitar toko.

Hasil dari penelitian ini mempunyai hasil yang berbeda, dimana membuktikan store layout tidak berpengaruh signifikan terhadap customer satisfaction yang dimana hal ini didukung oleh pendapat (Silva \& Giraldi, 2010) bahwa aspek layout sama sekali tidak berdampak pada kepuasan pelanggan. Sedangkan terdapat aspek-aspek lain yang akan berpengaruh terhadap kepuasan pelanggan, seperti assortment, convenience, reputation, price, dan service.

Melalui wawancara kecil yang penulis lakukan tentang store layout ready to eat bakery Surabaya tidak berpengaruh terhadap customer satisfaction, dari segi alokasi ruang, penempatan ruangan, dan lokasi penempatan ruangan. Alokasi luas ruangan ready to eat bakery Surabaya memiliki pengelompokan produk yang kurang sesuai menurut pelanggan, dilihat dari susunan pengelompokkan. Penempatan meja/ kursi ready to eat bakery Surabaya kurang nyaman menurut pelanggan, dikarenakan pelanggan ready to eat bakery Surabaya lebih banyak take away atau delivery order. Lokasi cashierready to eat bakery Surabaya untuk proses transaksi kurang sesuai menurut pelanggan, dimana posisi cashierterdapat agak diujung ruangan.

\section{Food Quality terhadap Customer Satisfaction}

Penelitian ini memiliki hasil bahwa food quality ready to eat bakery Surabaya memiliki pengaruh terhadap customer satisfaction. Pada hasil penelitian diketahui bahwa tidak adanya pengaruh secara signifikan dengan nilai uji $T$-statistic $>1.96$ yaitu 9,09.

Penelitian ini mempunyai hasil yang membuktikan bahwa food quality berpengaruh signifikan terhadap customer satisfaction yang dimana hal ini sesuai dengan beberapa pendapat (Rozekhi et al., 2016) bahwa kualitas makanan dan kepuasan, memainkan peranan penting dalam menentukan kepuasan pelanggan terhadap restoran, (Hanaysha, 2016) bahwa kualitas makanan yang dapat merangsang kepuasan pelanggan dalamkonteks industri restoran, dan (Nor Fadillah Binti Ahmad Shariff et al., 2015) bahwa selain kualitas pelayanan, beberapa faktor penentu lain dari kepuasan pelanggan dengan Chinese Muslim restaurants, yaitu kualitas makanan yang juga menentukan kepuasan pelanggan.
Ready to eat bakery Surabaya telah berupaya menciptakan inovasi dan variasi yang enak, menarik, dan membuat pelanggan puas dengan menuyang disajikan. Dalam analisa deskriptif, dimensi variabelvariabel juga menunjukan kesetujuan pelanggan akan berbagai macam dan bentuk ready to eat bakery Surabaya, yang berhubungan baik terhadap customer satisfaction.

\section{Customer Satisfaction terhadap Repurchase Inten- tion}

Penelitian ini memiliki hasil bahwa customer ready to eat bakery Surabaya memiliki pengaruh terhadap repurchase intention secara signifikan dengan nilai uji $T$-statistic $>1.96$ yaitu 19,86.

Penelitian ini mempunyai hasil yang menunjukkan bahwa customer satisfaction berpengaruh signifikan terhadap repurchase intention yang dimana hal ini sesuai dengan pendapat (Ibzan et al., 2016) dimana membangun hubungan antara kepuasan pelanggan dengan minat beli ulang, tidaklah mudah untuk dilakukan oleh banyak perusahaan. Terdapat tiga alasan utama variabilitas yaitu, mencakup batas kepuasan dimana konsumen yang puas memiliki berbagai tingkat pembelian kembali dengan karakteristik yang berbeda, respon bias (penuh prasangka) peringkat yang diperoleh dari survey mungkin tidak mewakili gambaran sebenarnya karena karakteristik konsumen yang berbeda, non-linear (tidak sebanding) bahwa fungsi kepuasan pembelian kembali mungkin nonlinear dan berbeda untuk konsumen yang berbeda. Hubungan kepuasan pelanggan dan minat beli ulang terpengaruh oleh karakteristik konsumen. Dapat dikatakan bahwa perusahaan harus memberikan kepuasan pada setiap karakter- karakter pelanggan.Jika pelanggan merasa puas, dengan sendirinya dia akan melakukan pembelian kembali terhadap perusahaan tersebut.

Ready to eat bakerySurabaya yang memberikan kepuasan terhadap pelanggan dengan selalu berusaha memenuhi dan melayani kebutuhan dalam bidang bakerydengan baik maka pelanggan akan merasa puas terhadap ready to eat bakery Surabaya. Sesuai dengan hasil dari kuisioner yang telah disebar dan berdasarkan analisa deskriptif dimensi, customer satisfaction terhadap repurchase intention menunjukkan kesetujuan pelangganterhadap terciptanya customer satisfaction dan repurchase intention di ready to eat bakery Surabaya.

\section{KESIMPULAN DAN SARAN}

Berdasarkan penelitian diatas, dapat dilihat bahwa variabelfood quality merupakan sebuah predictor penting yang secara statistik berpengaruh signifikan 
terhadap customer satisfaction sebagai intervening pada repurchase intention. Hal ini ditunjukkan oleh sebagian besar pelanggan yang setuju bahwa ia mendapat kualitas makanan yang positif pada saat melakukan pembelian di ready to eat bakery Surabaya. Berdasarkan path coefficient menunjukan, bahwa dalam penelitian ini store layout terhadap customer satisfaction memiliki hubungan yang lemah.

Sehingga dalam ready to eat bakery Surabaya repurchase intention atau pembelian ulang akan terjadi apabila pelanggan memiliki rasa kepuasan yang kuat dengan ritel. Hal ini dapat terjadi karena food qualityready to eat bakery Surabaya yang selalu memberikan dan memperhatikan variasi, inovasi, rasa, dan penampilan demi memenuhi kebutuhan, rasa senang, dan pengalaman yang menimbulkan kepuasan pelanggan.

\section{DAFTAR PUSTAKA}

Abdillah, W., \& Hartono, J. (2015). Partial Least Square (PLS) Alternatif Structural Equation Modeling (SEM) dalam Penelitian Bisnis. Yogyakarta: Andi Offset.

Al-Msallam, S. (2015). Customer Satisfaction and Brand Loyalty in the Hotel Industry. European Scientific Journal, I(October), 1857-7881.

Arshad, A., Sabir, H. M., \& Zia, M. (2014). Determinants of Super Store Customer Satisfaction in Pakistan, 5(11), 111-117.

Bachdar, S. (2016). Transformasi Ready to eat bakery Menjadi Jaringan Ritel Cake Shop. Retrieved March 1, 2017, from http://marketeers.com/transformasi-harvest-menuju-jaringan-ritel-cake-shop/

Elbers,T. (2016). The effects of in-store layout- and shelf designs on consumer behavior.

Goswami, S., Gupta, N., \& Professors, A. (2013). A Lookat Implications of Changing Store Layout and Design in India - bvimsr's. Journal of Management Research, Volume-5, Issue-1, April 2013 | Bharati IMSR Journal. Retrieved from http://www.academia.edu/12214973/A_Look_at Implications_of_Changing_Store_Layout_and Design_in_India_-_bvimsr_s_Journal_of_Management_Research_Volume-5_Issue-1_April_2013
Hanaysha, J. (2016). Testing the Effects of Food Quality, Price Fairness, and Physical Environment on Customer Satisfaction in Fast Food Restaurant Industry. Journal of Asian Business Strategy, 6(2), 31-40. https://doi.org/10.18488/ journal.1006/2016.6.2/1006.2.31.40

Ibzan, E., Balarabe, F., \& Jakada, B. (2016). Consumer Satisfaction and Repurchase Intentions, 6(2), 96-100.

Malholtra. (2004). Marketing Research. Prentice Hall.

Nor Fadillah Binti Ahmad Shariff, S., Binti Omar, M., Nurhanifah Binti Sulong, S., Adilin Binti Mohd Abd Majid, H., Binti Mohamad Ibrahim, H., Binti Jaafar, Z., \& Shah Kamal Bin Ideris, M. (2015). The Influence of Service Quality and Food Quality Towards Customer Fulfillment and Revisit Intention. Canadian Social Science, 11(8), 110-116. https://doi.org/10.3968/7369

Rozekhi, N. A., Hussin, S., Siddik, A., Abd, K., Siddiqe, R., \& Ab, P. D. (2016). The Influence of Food Quality on Customer Satisfaction in Fine Dining Restaurant: Case in Penang, 2(2), 45-50.

Shaharudin, M. R., Mansor, S. W., \& Elias, S. J. (2011). www.cscanada.org Food Quality Attributes among Malaysia's Fast Food Customer. International Business and Management, 2(1), 198-208. https://doi.org/10.3968/j.ibm.1923842 820110201.015

Sihombing, M., \& Djatikusuma, E. S. (2014). Analisis Pengaruh Citra Toko Terhadap Kepuasan Konsumen Carrefour Palembang Square Mall, 4(1), 49-57.

Silva, T. S., \& Giraldi, J. de M. E. (2010). The influence of store image on customer satisfaction: a case study of a shoe store. Brazilian Business Reviewview, 7(2), 60-77. Retrieved from http:// www.redalyc.org/pdf/1230/123021648004.pdf

Sugiyono. (2007). Metode Penelitian Pendidikan Pendekatan Kuantitatif, Kualitatif, dan $R \& D$. Bandung: Alfabeta.

Tren Ritel di Indonesia. (2016). Retrieved March 1, 2017, from http://www.propertyandthecity.com/ index.php/property-trend-list/671-tren-ritel-diindonesia 